\title{
Identification of Aspergillus Nomius in Floral Visitors of Brazil Nuts
}

Fernanda Massi (I), Rafael Penha (I), Marcelo Casimiro (I), Helena Viaro (I), Josué Silva (I), Larissa Ferranti (I), Maria Helena Fungaro

(I) UEL - Universidade Estadual de Londrina (Rodovia Celso Garcia Cid, Km 380 - Campus Universitário, Londrina - PR, 86057-97)

\section{Resumo}

The occurrence of aflatoxins in Brazil nuts is the main obstacle on their commercialization. The soil has been systematically recognized as the dominant source of aflatoxigenic fungi that contaminate Brazil nuts. However, their occurrence in nuts collected from the tree (Bertholetia excels) was recently reported. Among the aflatoxigenic fungi, Aspergillus nomius that belongs to section Flavi has been described as the main culprit for the presence of aflatoxins in Brazil nuts. A. nomius belongs to A. nomius clade besides A. pseudonomius and A. bombycis. Remarkable, their identification on the basis of morphological features is very difficult. In the present study, the $\beta$-tubulin gene sequences of all taxa belonging to the A. nomius clade, available in GenBank database (a total of 50), accessed at 6/14/2014) were used to design a polymerase chain reaction (PCR) primer pair (BtubNomF/ BtubNomR) to amplify A. nomius DNA only. In order to predict their specificity to A. nomius strains, the primer pair was tested in silico against all available sequences of section Flavi species. Only A. nomius strains sequences showed $100 \%$ of identity with the primer pair here designed. In vitro assays confirmed the BtubNomF/BtubNomR specificity supporting its utility for detecting and identifying A. nomius. Then we investigated the occurrence of A. nomius in floral visitors of B. excelsa tree by means of PCR and A. nomius was detected in the following bees: Xylocopa frontalis, Bombus transversalis,

\footnotetext{
Referência:

Fernanda Massi, Rafael Penha, Marcelo Casimiro, Helena Viaro, Josué Silva, Larissa Ferranti, Maria Helena Fungaro.Identification of Aspergillus Nomius in Floral Visitors of Brazil Nuts. In: Anais do 12 - Congresso Latinoamericano de Microbiologia e Higiene de Alimentos - MICROAL 2014 [= Blucher Food Science Proceedings, num.1, vol.1]. São Paulo: Editora Blucher, 2014. 
Centris denudans, C. ferruginea and Epicharis flava. The presence of A. nomius in visitor bees of Brazil nuts opens new avenues for increasing the knowledge about the contamination process of Brazil nuts by aflatoxin producing fungi.

Palavras-Chave: Aspergillus nomius, Brazil nuts, floral visitors Agência de Fomento: CNPq, CAPES, Fundação Araucária 